La emigración irlandesa decimonónica tras la gran hambruna, parte intrínseca del carácter irlandés

Ester Díaz Morillo

UNED (España) 



\title{
La emigración irlandesa decimonónica tras la gran hambruna, parte intrínseca del carácter irlandés
}

\section{The $19^{\text {th }}$-Century Irish Migration after the Great Famine, an Intrinsic Part of the Irish Character}

\author{
Ester Díaz Morillo \\ UNED (España) \\ esterdiaz.92@gmail.com
}

Fecha de recepción: 22 de octubre de 2018

Fecha de aceptación: 3 de noviembre de 2020

\section{Resumen}

A lo largo de la historia han tenido lugar episodios de grandes crisis que transformarían irremediablemente la vida de millones de personas. Uno de estos acontecimientos fue la gran hambruna producida en Irlanda entre 1845 y 1851 , uno de los eventos más trágicos de nuestra historia contemporánea que dejaría profundas huellas en su población. Uno de sus efectos más graves fue la oleada migratoria sin precedentes que llevó a numerosos irlandeses especialmente hasta las costas norteamericanas. Este artículo pretende, por tanto, estudiar la migración irlandesa producida por la gran hambruna y las características especiales que mostró y que la hizo distinguirse del resto de olas migratorias europeas decimonónicas. La «nueva Irlanda» que se conformaría en lugares como Estados Unidos nunca perdería su vínculo con la isla y dejaría un legado imborrable en ciudades como Nueva York y Chicago.

Palabras Clave: Irlanda; Migración; Gran hambruna; Crisis; Estados Unidos

\footnotetext{
Abstract

Throughout history there have been episodes of major crisis which would inexorably transform the lives of millions. One of such events was the Great Famine that took place in Ireland between 1845 and 1851, which was one of the most tragic events in our contemporary history and which would leave important marks on its population. The great unprecedented migration wave which led countless
} 
Irish people, especially towards the North American coasts, was one of its gravest effects. The aim of this article, therefore, is to explore the Irish migration induced by this Great Famine and the special characteristics that it showed and that made it distinguishable from the rest of the migration waves from nineteenth-century Europe. The "new Ireland" which developed in places such as the United States would never lose its bond with the island and would leave an indelible legacy in cities like New York and Chicago.

Keywords: Ireland; Migration; Great Famine; Crisis; United States

\section{INTRODUCGIÓN}

A lo largo de la historia más reciente ha habido una serie de acontecimientos de gran relevancia que han cambiado el transcurso de la misma; sucesos que han influido en la trayectoria de diversos países al mismo tiempo, en una especie de efecto dominó. Episodios de grandes crisis que cambiarían la vida de millones de personas. Uno de esos acontecimientos fue la gran hambruna que se produjo en Irlanda entre 1845 y 1851, que dejaría profundas huellas en el país a nivel físico y moral, y que, a día de hoy, sigue considerándose como uno de los eventos más trágicos de la historia contemporánea. Transformaría lo más hondo del carácter irlandés, su sistema económico, su población, etc. A su vez, provocaría toda una reacción en cadena cuyos efectos son notables hasta hoy, tanto en Irlanda como en aquellos países que acogieron a la ola de refugiados que buscaban un futuro más próspero.

La gran hambruna irlandesa, también conocida en irlandés gaélico como an Gorta Mór o blianta an droch-shaoil («los años de la mala vida») (Ó Cuív, 2009), estuvo causada por la crisis de la patata y fue uno de los eventos más importantes de la historia migratoria, especialmente relevante para Estados Unidos, pues cambiaría la estructura social de ambos países irremediablemente. Esta gran crisis produjo una oleada migratoria sin precedentes de irlandeses que huían en busca de mejores condiciones de vida hacia Gran Bretaña, Canadá y Estados Unidos, entre otros destinos. Al igual que en la actualidad podemos observar las crisis de refugiados que llegan a nuestras costas, hace dos siglos muchos de aquellos emigrantes irlandeses llegaban en condiciones muy similares a las costas norteamericanas, sin apenas posesiones ni dinero para poder subsistir, en busca de un futuro que les había sido arrebatado en su patria. Así pues, los irlandeses se convirtieron en el segundo grupo étnico más importante en muchos de estos lugares.

Esta hambruna está tan profundamente arraigada en la historia irlandesa y norteamericana que ha dado lugar a numerosos estudios y debates al respecto durante décadas. Irlanda no se recuperaría de esta terrible pérdida, tanto económica como social, hasta bien entrado el siglo XX (Butterly, Shepherd, 2010) y sus consecuencias tendrían un largo efecto sobre el país y sus habitantes, como más 
adelante mostraremos. Es por ello que este episodio de la historia resulta de gran relevancia para su estudio, tanto dentro de su propio contexto temporal como en la actualidad, como diversos autores (Butterly y Shepherd, entre otros) han hecho, en un intento de mostrar la necesidad de aprender las lecciones de nuestra historia para remediar el presente actual de numerosos países que sufren crisis parecidas en diferentes continentes.

Se pretende aquí, por tanto, estudiar brevemente la gran hambruna y se encuadrará la migración irlandesa provocada por esta dentro de las grandes oleadas migratorias europeas del siglo XIX, así como se analizarán las particularidades que hacen que la migración irlandesa tenga un carácter propio y distintivo. Por último, se estudiará el asentamiento de los inmigrantes en el destino más común, Estados Unidos, analizando su impacto en estos lugares de destino, donde se conformaría una especie de «nueva Irlanda» que jamás perdería su vínculo con la isla Esmeralda y que tendría una gran repercusión en su nuevo hogar. El objetivo principal de este trabajo será el de analizar y caracterizar esa emigración irlandesa causada por esta crisis desde su situación y salida de Irlanda hasta su llegada y establecimiento concretamente en Estados Unidos.

El proceso de documentación, por tanto, ha estado basado primordialmente en una serie de investigaciones sobre la emigración irlandesa y su asentamiento en Estados Unidos. Destacan en la bibliografía estudios como los de Bayor y Meagher (1997), Fitzgerald y Lambkin (2009), Peter Gray (1999), Ó’Grada (1995, 2000) y O'Rourke y Williamson (2000), este último especialmente para enmarcar la emigración irlandesa dentro de la corriente migratoria europea.

\section{MIGRACIÓN EUROPEA EN EL SIGLO XIX}

El siglo XIX fue una época de grandes migraciones en la que millones de personas se desplazaron, especialmente desde Europa hacia América. En 1880 la cifra de emigrantes europeos hacia Norteamérica sobrepasaría por primera vez la de los esclavos africanos (Chiswick, Miller, 2014, p. 54). Las migraciones del siglo XIX y XX forman parte esencial de la historia europea reciente; por ello, los años que transcurrieron entre 1850 y 1914 han sido denominados por Timothy J. Hatton y Jeffrey G. Williamson como la época de las grandes migraciones europeas.

En segundo lugar, es importante recordar que las migraciones se expanden profusamente a finales del XIX principalmente debido a un motivo esencial: el desarrollo de las tecnologías industriales en general y del ferrocarril y el vapor en particular, que permiten desplazar a millones de personas fácilmente (Bagwell, 1988) rompiendo con las rigideces de los sistemas de transporte preindustriales. Por otro lado, el abaratamiento de los precios del transporte internacional, no solo de pasajeros, sino también de mercancías, permitió que muchos productos de fuera del continente llegaran a Europa, especialmente productos americanos, a un precio 
menor que el producto local, lo que acabaría arruinando a los productores europeos (Garrabou, 1988). Esto se tradujo en una caída de precios, que venía dada por el aumento de la productividad agraria en América (Simpson, 2001, p. 110). Este fenómeno es conocido como la crisis agraria finisecular (Garrabou, 1988).

Resulta importante caracterizar esta migración del siglo XIX, que muestra claras diferencias con respecto a las anteriores y posteriores. En este sentido, O'Rourke y Williamson (2000, pp. 123-124) nos ofrecen los siguientes datos. Los migrantes de principios de siglo eran especialmente agricultores y artesanos rurales que viajaban en familia con la intención de asentarse de manera permanente en un nuevo lugar. Sin embargo, a finales de siglo se observa un cambio en la caracterización de estos migrantes, entre los que abundaban sobre todo los varones jóvenes solteros, que supusieron un gran aumento en la mano de obra de los Estados Unidos. Por lo general, todos estos presentaban un perfil común: eran mano de obra no cualificada y contaban con una formación limitada. No obstante, estas mismas características los hacían más aptos a las condiciones laborales del país de destino.

La primera gran migración masiva se produjo en la década de 1840 debido tanto a la hambruna como a las revoluciones que se expandían por Europa. De hecho, sería en Irlanda donde estas migraciones masivas comenzaron. Cada nueva oleada migratoria sería mayor que la anterior, hasta llegar a la Primera Guerra Mundial. En este sentido, la migración procedente de Irlanda supone una excepción a esta regla, ya que presenta una tendencia descendente. Esta característica se explica en parte por la convergencia entre los salarios irlandeses y los de aquellos países de destino, es decir, que la brecha salarial se redujo gradualmente (O'Rourke, Williamson, 2000, pp. 123-125).

\section{CARAGTERIZAGIÓN DE LA MIGRACIÓN IRLANDESA EN EL SIGLO XIX}

\subsection{Causas de la emigración}

Antes de analizar las características de las migraciones irlandesas del siglo XIX conviene saber a qué se debieron estas oleadas migratorias sin precedentes en la historia europea. La razón principal ha de buscarse en la gran hambruna y en las malas circunstancias que se vivieron en el país en aquel momento. En 1845 el hongo Phytophthora Infestans llegó hasta los cultivos de Irlanda y gran parte de la Europa occidental. Su origen probablemente se encuentra en los Andes. Este parásito arruinó los cultivos de patatas en diversos países, lo que tendría graves consecuencias y llegaría a causar la muerte de millones de europeos y la migración de otros tantos más (Meagher, 2005). No se llegaría a encontrar un remedio contra este parásito hasta la década de 1890 (Fitzgerald, Lambkin, 2009, p. 176). 
En Irlanda fue especialmente devastador, ya que en este país había mucha más gente que dependía de manera directa de la patata, que había sido introducida en el país en 1596 y que desde comienzos del siglo XVIII era un alimento básico (Morehouse, 1928, p. 579). Por lo general, un hombre adulto consumía en la época hasta 6.4 kilos de patatas al día, mientras que las mujeres consumían 5.1. Fue a finales de 1845 cuando el hongo llegó a los cultivos, que quedaron prácticamente destrozados en 1846. Al año siguiente se pensó que lo peor ya había pasado; tal fue así que en 1848 decidieron sembrar completamente todos los cultivos. Sería aquel año cuando las autoridades británicas declararan oficialmente terminado el estado de emergencia. Sin embargo, la plaga volvió a aparecer y a finales de 1848 había destrozado nuevamente casi todas las plantaciones (Meagher, 2005). Sin patatas, su alimento básico, ni ningún otro tipo de substituto, los irlandeses no contaban con otro sustento y se calcula que falleció más de un millón de personas como consecuencia (Ranelagh, 1994). Algunos murieron directamente de hambre, pero la mayoría falleció debido a las enfermedades que se propagaron, como la disentería y el cólera. Por último, cabe destacar que murieron muchos más hombres que mujeres. Muchos de los fallecidos tuvieron que ser enterrados en fosas comunes ante la gran cifra de defunciones.

Desde entonces comenzaron los debates sobre las posibles causas de esta catástrofe. Por un lado, los británicos señalaban el crecimiento de la población irlandesa y su excesiva dependencia de la patata como origen de todos los males. Ó'Grada expone que la población irlandesa, de hecho, se cuadriplicó entre 1780 y 1845, pasando de tan solo 2 millones a 8.2 millones, y, justo antes de la hambruna, Irlanda tenía la mayor densidad de población de Europa (Butterly, Shepherd, 2010 , p. 44). Por otro lado, los nacionalistas irlandeses consideraban que esto era la consecuencia directa de tres factores: los efectos a largo plazo que acarreaba el sistema agrario tan opresivo e ineficaz impuesto sobre los irlandeses, la codicia y dilapidación de los propietarios de las tierras, y la insensibilidad del gobierno británico para con Irlanda. En este sentido, hay que hacer una concesión al respecto, ya que en parte es cierto que la doctrina del laissez-faire causó grandes daños en la situación de Irlanda. Su situación contrastaba enormemente con la de Gran Bretaña, cuna de la revolución industrial y la economía más avanzada del mundo hasta entonces, que siguió floreciendo económicamente incluso cuando Irlanda sufría las peores consecuencias de la hambruna (Ó'Grada, 1992). Así, Miller (1988, p. 286) apuntó que la gran hambruna fue el resultado del estatus colonial de Irlanda y su sistema social extremadamente desigual.

Diversos historiadores, como Ó'Grada o Donnelly, entre otros, reconocen que las políticas británicas sobre el país no hicieron nada para poner fin o al menos ayudar a la población en aquellos momentos de auténtica tragedia, más bien lo contrario; Irlanda quedó prácticamente abandonada a su suerte y ni los líderes británicos ni irlandeses hicieron nada por socorrer los habitantes de la isla (Meagher, 2005). La acusación más persistente y amarga contra los gobernantes es que el país seguía 
exportando alimentos cuando su propia gente moría de hambre, una cruel ironía que se mantuvo incluso en los tiempos de crisis y que provocó disturbios entre la población ante la negativa del gobierno de prohibir las exportaciones. Lo que sí podemos concluir, como apunta Donnelly (2012), es que la pobreza de gran parte de la población irlandesa fue el factor principal que convirtió la hambruna en un fenómeno tan destructivo.

\subsection{Migración irlandesa: cifras, orígenes y destinos}

La emigración irlandesa comenzó bastante antes de la llegada de la gran hambruna de la década de 1840 y puede remontarse hasta antes de 1800; sin embargo, será entonces, a finales de 1846, cuando esta emigración adquiera un carácter nuevo y extraordinario, y cuando, además, se convierta propiamente en una emigración masiva. La clave de todo ello reside en la migración en cadena, un factor de gran importancia en otros países además de Irlanda, pero especialmente determinante en el caso irlandés. Algunos cálculos, como nos indican Glynn (2011) y Fitzgerald y Lambkin (2009), apuntan a que en un siglo, contando desde principios del siglo XIX hasta el estallido de la Primera Guerra Mundial, más de seis millones de irlandeses emigraron hacia América. El caso irlandés, pues, llama la atención no solo por las altas cifras de emigrantes, sino por lo elevadas que resultan estas comparadas con la población de la isla. Así pues, la tasa migratoria irlandesa llegaba hasta duplicar la de otros países europeos. Por esta razón, esta emigración irlandesa es una de las grandes movilizaciones de población de todo el siglo XIX.

Pese a que a posteriormente la tasa de emigración disminuyera, no lo hizo lo suficiente y las cifras continuaron siendo elevadas, debido a las remesas que mandaban los que ya se hallaban asentados en el Nuevo Mundo; por este motivo, la migración en cadena es una de las características más intrínsecas de la migración irlandesa. Este tipo de migración se beneficiaba de las remesas que enviaban los anteriores migrantes a sus familias, posibilitando así la financiación de una nueva oleada de migrantes. Esto es lo que explica el hecho de que, aunque los salarios irlandeses comenzaron a subir, la tasa de emigración continuó siendo elevada. Esta persistencia será la característica esencial de la migración irlandesa de finales del siglo XIX y ninguna otra tradición migratoria europea comenzó tan pronto ni fue tan persistente en el tiempo - al menos cuatro siglos - (Fitzgerald, Lambkin, 2009).

Un nuevo fracaso en las cosechas de las patatas en 1848 desencadenó un éxodo masivo entre los inviernos de 1848-1849 y1849-1850, causando la despoblación de distritos enteros en Irlanda. En estos dos últimos años más de 200000 irlandeses partían hacia América anualmente. El pico se alcanzaría en 1851, cuando poco menos de 250000 irlandeses partieron de sus hogares, década desde la cual la cuota de emigración comenzará a descender (Gray, 1999). Baste mirar las cifras en perspectiva: recordemos que en total durante los años de la crisis y posteriores unos 
dos millones y medio de irlandeses abandonaron Irlanda, mientras que en los casi 65 años transcurridos entre 1850 y 1913 emigraron unos cuatro millones y medio (Gray, 2004; Glynn, 2011).

Así pues, se puede llegar a la conclusión de que la emigración provocada por la gran hambruna irlandesa fue capaz de impulsar unas tasas de emigración posteriores de hasta seis por mil al año (O'Rourke, Williamson, 2000, p. 135). No cabe duda, pues, de que la hambruna contribuyó a que las tasas de emigración irlandesa fueran y permanecieran elevadas hasta bastante después de las décadas de 1840 y 1850 . El gran éxodo, no obstante, tuvo lugar entre los años 1847 y 1854, lo que dio lugar al origen de la posterior emigración irlandesa, como se ha visto, y a la despoblación del país.

En Irlanda, esta gran hambruna tuvo una consecuencia muy directa: prácticamente toda una generación de irlandeses desapareció de la isla, bien por fallecimiento, bien por la emigración. La elevada tasa de mortalidad junto a la también alta y constante tasa migratoria provocaron, especialmente esta última, un dramático descenso de la población, que pasó de más de 8 millones de habitantes en la isla en la década de 1840 a los 4.4 millones en 1911 (Glynn, 2011). Es más, la población de Irlanda, que hasta el siglo XIX no había hecho más que crecer a un buen ritmo, en aquel momento se redujo y se convirtió así en el único lugar europeo en el que, en lugar de aumentar, su población disminuyó (Fitzgerald, Lambkin, 2009).

Sobre los destinos de estos emigrantes cabe resaltar que los que cruzaron hasta Gran Bretaña para establecerse allí eran más pobres que los que decidieron hacer el viaje transatlántico. Aproximadamente unos 500000 irlandeses permanecieron en Gran Bretaña, especialmente en ciudades portuarias como Liverpool. Unos 289000 irlandeses, emigraron a Australia y Nueva Zelanda. Mientras tanto, hasta 60000 irlandeses emigraron hacia Sudáfrica, Argentina y otros lugares (Miller, 1988, p. 346). No obstante, por lo general, los emigrantes preferían ir a lugares más tradicionales dentro de las cadenas migratorias irlandesas, como Estados Unidos, asentándose sobre todo en los estados del noroeste.

\subsection{Perfil del emigrante irlandés}

En la primera mitad del siglo XIX los hombres conformaban la mayor parte de la emigración irlandesa. No obstante, esta tendencia cambiaría a partir de 1850, ya que las mujeres irlandesas de los medios rurales sufrieron un importante deterioro en su situación socio-económica, por lo que muchas decidieron entonces emigrar (Glynn, 2011). Así pues, a mediados del siglo XIX aproximadamente la mitad de la diáspora irlandesa era femenina. Desde 1871 a 1971, de hecho, la tasa de mujeres emigrantes era mayor que la de los hombres, hasta tal punto que algunos hablan de «desfeminización» de la Irlanda rural y, por extensión, de la «feminización» de la diáspora irlandesa. Mientras que la norma europea era que los hombres emigraban en 
cifras mucho mayores, este equilibrio parejo de géneros es otra característica propia de la experiencia migratoria irlandesa (Diner, 1983). Si tenemos esto en cuenta, no es de extrañar que las comunidades irlandesas en Estados Unidos también fueran predominantemente femeninas.

En 1900, por ejemplo, las mujeres conformaban el $53.8 \%$ de los inmigrantes, cuando a principios de siglo tan solo llegaron a suponer el $35 \%$. Estas mujeres eran por lo general más jóvenes que los hombres, muchas de las cuales entre los 15 y 19 años entraban a trabajar en el servicio doméstico, como se verá más adelante (Travers, 1995, p. 147). Los hombres emigrantes, por su parte, tenían entre 18 y 35 , por lo general (Ó Cuív, 2009). Por otro lado, las mujeres irlandesas fueron las que más contribuyeron a la migración en cadena, especialmente en el caso de hermanas y tías.

Las jóvenes solteras irlandesas, por lo general, se enfrentaban a dos opciones: bien podían cruzar el Atlántico y convertirse en mujeres trabajadoras e independientes, o bien podían conformarse con el hecho de trabajar para sus familias en Irlanda sin remuneración a cambio (Glynn, 2011). Las hijas no tenían derecho sobre el terreno familiar, ya que este era heredado tan solo por el primogénito. Quizá por ello fueron muchas las que tomaron la decisión de partir hacia América. Numerosas mujeres habrían tenido la esperanza de un progreso económico tal que les garantizara matrimonios respetables y un buen estatus (Diner, 2009). Esta sería la motivación principal para que estas muchachas alcanzaran mayores niveles de educación que los hombres en su tierra natal. Tampoco podemos obviar el caso de mujeres que rechazaron el matrimonio y decidieron ingresar en órdenes religiosas. Algunas de estas se ordenaron como religiosas al emigrar y otras, tras tomar los hábitos, emigraron como misioneras (Guinnane, 1997; Walsh, 2002, pp. 141-144).

Por un lado, en su mayor parte, los migrantes eran agricultores, aunque también hubo un gran número de artesanos, como, por ejemplo, sastres especializados. Por ello, la mayoría de estos emigrantes irlandeses eran de un trasfondo más humilde en comparación con los de épocas anteriores (Glynn, 2011). Por otro, la gran mayoría de los emigrantes irlandeses eran católicos, sin embargo, los protestantes también continuaron emigrando en este siglo e incluso en el XX.

No obstante, no podemos olvidar el caso de la emigración forzada -por causas políticas, por condenas a trabajos forzados o prisión, etc.-, aunque también supusiera una minoría. Así, por ejemplo, hubo una fuerte respuesta política a la gran hambruna en 1848 por parte de los Young Irlanders, pertenecientes al movimiento de la Joven Irlanda, muchos de los cuales contemplaban la opción de rebelarse contra los británicos. Esto derivó en que algunos de sus líderes o fueran deportados a Tasmania (como John Mitchel, William Smith O'Brien y Thomas Francis Meagher) o huyeran al exilio en Estados Unidos (como Thomas D'Arcy McGee). Thomas Francis Meagher y John Mitchel consiguieron más adelante escapar hacia Estados Unidos, donde fueron recibidos como héroes. Los escritos que varios de ellos dejaron, junto a 
los testimonios de otros que emigraron debido a la crisis de la patata, alimentaron el violento desarrollo de una tradición del republicanismo irlandés en América entre la siguiente generación de inmigrantes (Fitzgerald, Lambkin, 2009: 180) y cambiaron el sentir sobre la emigración irlandesa para siempre, politizando especialmente las calamidades de la gran hambruna (Miller, 1988: 311).

\subsection{El viaje transatlántico}

Cuando había una gran demanda, como ocurrió durante la gran hambruna, lo más frecuente era que se produjera un hacinamiento que podía derivar en casos infames como los coffin-ships, que eran embarcaciones de madera no preparadas para el transporte humano que se convirtieron en auténticos ataúdes flotantes (Coogan, 2002, p. 370). Sin embargo, el hacinamiento continuó siendo un problema en la época del vapor. Las travesías directas eran muy poco frecuentes, aunque existían líneas como la de Derry-Filadelfia, por lo que la inmensa mayoría viajaba en primer lugar a Gran Bretaña. La mayor parte salía desde el puerto de Liverpool, que se había convertido en la segunda ciudad más importante en Inglaterra y contaba con un valioso puerto comercial. Se calcula que, a mediados de la década de 1840, más un de $90 \%$ de los emigrantes irlandeses partían hacia Estados Unidos o Canadá desde esta ciudad portuaria inglesa (Meagher, 2005, pp. 74-75).

Las travesías hasta Norteamérica no eran nada sencillas y solían durar alrededor de seis semanas. Desde Liverpool embarcaban muchas naves con destino a Nueva York, en una ruta directa que tomarían muchos irlandeses. Naturalmente, esta horrible situación para muchos se acabó convirtiendo en un negocio para otros. Los mayores beneficiarios fueron los propios propietarios de las embarcaciones y los especuladores. La mayoría de las embarcaciones eran demasiado pequeñas o inadecuadas para transportar a tantos pasajeros en una travesía tan larga. Especialmente horribles eran las condiciones en los barcos con rumbo a Canadá; el año 1847 fue conocido como el Black '47 porque al menos 20000 irlandeses fallecieron de camino a Canadá (Meagher, 2005, p. 75). En general, entre 1845 y 1851 alrededor de cincuenta embarcaciones naufragaron, provocando la muerte de miles de irlandeses (Coogan, 2002).

La gran mayoría de campesinos irlandeses nunca se había alejado de sus hogares, por lo que era común que muchos sufrieran desorientación tras arribar a Liverpool. Esta situación fue aprovechada por numerosos ladrones que hacían su negocio robando equipajes y dinero. No obstante, aquí no acababan las penurias de estos irlandeses. La situación en los barcos no era mejor. El propio embarque se convertía en un caos la mayoría de las veces. Además, las malas condiciones higiénicas de los barcos junto al frío y humedad hacían que se desarrollaran enfermedades como la disentería y los mareos por el viaje marítimo, incluso el tifus y el cólera, que, su vez, podían desembocar en deshidratación y debilitamiento (Gray, 1999). 


\section{DESTINO DE LOS MIGRANTES: NUEVA YORK Y BOSTON}

Estados Unidos se convirtió en un auténtico imán para la inmigración irlandesa. Fue, de hecho, la inmigración que llegó durante la hambruna la que ayudó a establecer una base en el país que continuaría renovándose durante décadas después gracias a las remesas, como se ha visto anteriormente. En el caso de los irlandeses, estos pusieron rumbo hacia la costa este de Estados Unidos, especialmente a Nueva York, Boston y Filadelfia (Glynn, 2011) y, más adelante, llegarían hasta San Francisco en la costa oeste.

Se calcula que en 1847 más de 37000 irlandeses llegaron a Boston, lo que supuso un aumento de población de un tercio (Keating, 1996, p. 67). En 1860, los irlandeses conformaban el $36 \%$ de la población extranjera de la ciudad (McIlwraith, Muller, 2001, p. 203). Boston no estaba bien preparada para recibir a los miles de inmigrantes que llegaban a su puerto. En esta ciudad las condiciones eran inferiores a las de Nueva York. No obstante, desde el año 1848 la mayoría de emigrantes irlandeses pusieron rumbo directo a la ciudad de Nueva York. Entre los años 1847 y 1851 hasta 1.8 millones de inmigrantes llegaron a la ciudad de Nueva York, entre ellos 848000 irlandeses. Esta ciudad tuvo menores problemas a la hora de absorber la gran cantidad de inmigrantes que arribaban de todas partes (Bayor, Meagher, 1997, p. 91). Así pues, Nueva York se convirtió en la ciudad con la comunidad irlandesa más grande de los Estados Unidos.

La mayoría de los inmigrantes irlandeses vivía en el Lower East Side, no muy lejos de donde desembarcaron. No se llegó a formar ningún gueto irlandés como tal ni se apropiaron de ningún barrio en concreto, aunque conformaran una mayoría en ciertos distritos; incluso en el barrio de Five Points los irlandeses compartían las calles con otros grupos étnicos. De hecho, los irlandeses en Nueva York siempre estaban cambiando de vivienda tanto dentro de la ciudad como fuera de la misma. Asimismo, hay que tener en cuenta que no debe asociarse estrictamente a los irlandeses con la pobreza más absoluta, como se ha hecho en la mayoría de los casos, pues también había profesores, abogados, médicos, etc., especialmente entre los inmigrantes que ya llevaban más tiempo asentados en el Nuevo Mundo y habían ascendido en la escala socioeconómica (Bayor, Meagher, 1997, p. 94).

\section{LA DIÁSPORA IRLANDESA EN AMÉRICA}

La mayoría de la población inmigrante irlandesa vivía en los barrios pobres y marginales de las ciudades en las que se establecían, donde podían subsistir de manera más económica. La mayor parte de los isleños que dejó su tierra como consecuencia de la gran hambruna se estableció en los trabajos peor pagados, menos cualificados y más peligrosos. Todo esto se debe a que la gran mayoría de los irlandeses habían 
trabajado en su patria como trabajadores agrícolas rurales y, por lo tanto, no llevaban consigo otras destrezas profesionales. Asimismo, los inmigrantes tenían dificultades a la hora de acceder a algunos oficios porque los trabajadores nativos de Estados Unidos conspiraban en su contra. En las décadas siguientes, la cifra de irlandeses en las cárceles, psiquiátricos y asilos habilitados para pobres sobrepasaba la media (Riis, 2011). De hecho, los irlandeses llegaron a conformar el $60 \%$ de los internos en el manicomio de Nueva York entre los años 1849 y 1859, la mayoría de los cuales eran mujeres (Meagher, 2005, p. 78).

Muchos eran marginados por un fuerte sentimiento anticatólico en la sociedad norteamericana, que fue a peor a raíz de las migraciones tras la gran hambruna. La Orden de Orange irlandesa, una organización protestante también establecida en Estados Unidos, y el nativismo americano promovieron la discriminación contra los católicos de toda clase entre las décadas de 1850 y 1860. Por esta razón, algunos irlandeses decidieron convertirse o adoptar nombres y costumbres «americanas», mas la gran mayoría se replegó a la relativa seguridad de las comunidades e instituciones católico-irlandesas que surgieron para ofrecerles protección, como veremos en el siguiente apartado.

Las comunidades irlandesas se mantuvieron firmes, unidas y activas debido a la continua emigración, la discriminación y el interés político sobre su patria. Este último punto, fue de gran importancia, pues en el imaginario colectivo quedó congelada en el tiempo una imagen de la patria fundamentalmente anti-británica. Estos sentimientos fueron articulados por los miembros del movimiento de la Joven Irlanda que se encontraban en el exilio y cuya nota más característica sería el eterno odio hacia Gran Bretaña (Miller, 1988, pp. 334-335). Todos estos inmigrantes irlandeses de la gran hambruna se transformaron en «hiberno-americanos», crearon sus propias instituciones sociales y sus prácticas étnicas, dando lugar a una cultura altamente expresiva y pintoresca (Diner, 2009, p. 114).

\section{REDES DE INMIGRANTES: EJES DE UNIÓN E IDENTIDAD}

El recurso más importante para todo recién llegado era el tener vínculos con familiares o amigos que ya se encontraban allí, personas capaces y dispuestas a ayudarles. En este sentido, contribuyeron en gran manera las remesas que los migrantes continuaron enviando a sus familias en Irlanda. Las redes de inmigrantes que se establecieron facilitaron la migración así como la adaptación al nuevo país. Además de los comercios y bares, que podían convertirse en clubes y lugares de reunión, hubo otros tres importantes focos cohesionadores e identitarios de la comunidad irlandesa en Estados Unidos: la Iglesia Católica, el Partido Demócrata y el nacionalismo irlandés (Gray, 1999; Miller, 1988, p. 328). 


\subsection{El Partido Demócrata}

Varios inmigrantes irlandeses o irlandeses nacidos en América ya se habían abierto camino en la directiva del Partido Demócrata en Nueva York en la década de 1860. Pero, ¿por qué el Partido Demócrata? Por una parte, los irlandeses católicos prefirieron este partido porque ofrecía una alternativa al Republicano o Whig, más insistentes en la imposición de la cultura protestante (Meagher, 2005, p. 89). Por lo tanto, en oposición al republicanismo nativista, los irlandeses votaban y aspiraban a estar entre las líneas del Partido Demócrata. Este, en agradecimiento por sus votos, ofrecía a cambio ciertos beneficios (puestos de trabajo, alimentos, préstamos, etc.). A mediados de 1850 los irlandeses empezaron a tomar el control de la política de la ciudad. Tammany Hall era el centro de la política neoyorquina, dominado largamente por William Tweed. Tras la caída de Tweed, serían los irlandeses los que ocuparían los cargos de liderazgo del Partido Demócrata. El primer líder irlandés de Tammany Hall fue John Kelly en 1872, mientras que el primer alcalde irlandés de Nueva York fue William R. Grace en 1880 (Bayor, Meagher, 1997, p. 212).

A cambio de su fidelidad en las votaciones, el Partido Demócrata ofrecía en numerosas ocasiones puestos dentro del partido u otros puestos de poder. En este sentido, destacan dos departamentos muy empleados en la época para el ascenso político: el de policía y el de bomberos. Los inmigrantes irlandeses normalmente usaban sus posiciones en el departamento de policía como trampolín para el progreso político. Precisamente este departamento era de las pocas instituciones gubernamentales que contrataba irlandeses en cifras considerables; por ejemplo, en 1860 había 309 irlandeses en el cuerpo de policía neoyorquino, mientras que tan solo 84 eran de origen alemán (Bayor, Meagher, 1997, p. 97). Otro camino hacia la prominencia política era a través del departamento voluntario de bomberos, una de las instituciones más pintorescas de la antigua Nueva York. Los bomberos eran los héroes de la mayoría de los barrios más humildes de Nueva York. Pese a ser meros voluntarios, se tomaban muy en serio sus responsabilidades. (Anbinder, 2010, p. 183).

\subsection{La Iglesia Católica}

La Iglesia Católica estaba presente en todas las poblaciones y barrios del país. Asimismo, se conformaría como el agente de control más eficaz en los límites de la comunidad. La iglesia no alcanzó este poder durante los años de la gran hambruna. En la década de 1840 en la mayoría de ciudades era tan solo una organización limitada con un gran número de hombres y mujeres con poco conocimiento sobre su fe. Pero poco a poco la iglesia se fue haciendo con el control de la situación y contribuyó a hacer frente al creciente sentimiento anti-católico en Estados Unidos (Miller, 1988, pp. 331-333). Desde mediados del siglo XIX la iglesia católica en Estados Unidos estaba liderada por obispos de origen irlandés, lo cual fue aceptado por lo general por 
las demás comunidades inmigrantes católicas. El continuo crecimiento de su riqueza y respetabilidad fueron factores fundamentales en el auge de los irlandeses.

\subsection{El nacionalismo irlandés}

También durante los años de la gran hambruna se estableció un tercer y último polo de identidad: una nueva especie de nacionalismo hiberno-estadounidense. Los exiliados nacionalistas irlandeses en América ya habían plantado la semilla del nacionalismo, pues muchos de ellos, como John Mitchel, se habían refugiado en Estados Unidos. Así, por ejemplo, tenemos el movimiento de la Joven Irlanda, que mencionamos anteriormente; fue fundado en Irlanda por un grupo de periodistas y poetas románticos, entre otros jóvenes, y contaba con su propio periódico (Miller, 1988, pp. 308-309). Otro miembro del movimiento, James Stephens fundaría luego la Hermandad Republicana Irlandesa, una sociedad secreta con una filial en Estados Unidos.

Sin embargo, el pilar principal del nacionalismo en Estados Unidos fue el movimiento feniano, fundado poco antes de la Guerra Civil, que alcanzaría una popularidad extraordinaria en la década de 1860. El fenianismo fue el primer nacionalismo irlandés que consiguió convertirse en un verdadero movimiento de masas en América. Los fenianos tuvieron un grandísimo éxito al movilizar la opinión pública y se convirtieron en la organización étnica más influyente de la historia hiberno-americana. Al finalizar la guerra, el fenianismo contaba con 50000 miembros aproximadamente, muchos de ellos soldados entrenados (Miller, 1988, p. 336). Todos estos nacionalistas siempre mantendrían fuertes lazos con el movimiento en Irlanda.

Por tanto, el continuo crecimiento de la fuerza de la Iglesia Católica, el Partido Demócrata y el nacionalismo gradualmente dieron cohesión y coherencia a las nuevas comunidades hiberno-estadounidenses tras los años de la hambruna. No obstante, también hubo otras fuerzas de unión exteriores a la comunidad. La más importante es la de los Know Nothing, un partido político caracterizado por su ferviente prejuicio contra los inmigrantes y los católicos, que fue adquiriendo mayor poder a mediados de 1850. Este odio contribuyó a unir a los irlandeses católicos en torno a la Iglesia y el Partido Demócrata, así como acrecentó el sentimiento nacionalista (Meagher, 2005, p. 91).

\section{LAS MUJERES IRLANDESAS}

La experiencia migratoria de las mujeres irlandesas difiere en parte de la de los hombres y, como se explicó con anterioridad, la migración irlandesa se caracterizó y destacó precisamente por su feminización, por lo que también sobrepasaban en 
número a los irlandeses en Estados Unidos. Por todo ello, la experiencia femenina en este país merece una breve observación. Además de las familias o matrimonios que emigraron hacia Estados Unidos, otras tantas mujeres emigraron en busca de la emancipación económica y sexual, huyendo de la opresión de una sociedad católica y patriarcal como era la irlandesa. Otras mujeres partieron hacia el Nuevo Mundo porque creían que así serían capaces de facilitar la supervivencia familiar y cultural en Irlanda con el dinero y apoyo que pudieran enviar desde el otro lado del Atlántico. Esta migración femenina del siglo XIX se convirtió en modelo para las irlandesas del próximo siglo (Gray, 2004, p. 2).

Numerosas mujeres fueron conscientes de que sus oportunidades de matrimonio eran mayores en otros países, sobre todo en Estados Unidos, que en sus propias localidades. Una vez llegaban a América, las mujeres estaban más dispuestas a casarse que los hombres, pues tenían una clara intención de ascender en la escala social. En este sentido, el hecho de que la gran mayoría de ellas eran angloparlantes y estaban alfabetizadas les daba una gran ventaja sobre otras inmigrantes europeas (Fitzgerald, Lambkin, 2009, pp. 191-192).

La vida familiar en el Nuevo Mundo era muy similar a la que los irlandeses llevaban en su patria. Las mujeres continuaban teniendo un papel importante, fuerte y central. Sin embargo, otros aspectos cotidianos sí sufrieron cambios. Por ejemplo, la viudedad se convirtió en una experiencia mucho más frecuente en Estados Unidos, así como el abandono de la familia por parte del marido. Consecuentemente era más común que los hogares estuvieran dirigidos por las mujeres. Así pues, estas adquirieron un estatus superior a veces al de los hombres y tuvieron un papel más autoritario. Por otra parte, los irlandeses en Estados Unidos se casaban con menos frecuencia en comparación con el resto de inmigrantes (Diner, 1983).

La mitad de las mujeres irlandesas, aproximadamente, que emigraron hacia Estados Unidos trabajaban como empleadas domésticas en las ciudades (Glynn, 2011). En la década de 1850 el $80 \%$ de las mujeres que trabajaban en el servicio doméstico en Nueva York eran irlandesas y aún en 1900 el 60 \% de las irlandesas en Estados Unidos trabajan en este sector (Miller Topp, 2004, p. 226). Muchas de estas perseguían la emancipación económica como alternativa al matrimonio (Gray, 2004, pp. 2-3). Las criadas que vivían en la casa de las familias que la empleaban estaban en mejores condiciones. Por lo general, se alimentaban mejor y residían en barrios más seguros y limpios que otros inmigrantes. Pese a que su sueldo era igualmente bajo, recibían alojamiento y comida gratuitamente, por lo que podían enviar mayores cantidades de dinero a sus familias en Irlanda o incluso ahorrar(Anbinder, 2010, p. 126).

Aunque las horas de trabajo eran duras y largas, las inmigrantes podían presenciar y aprender los valores y conducta de los americanos de mejor posición económica (Miller Topp, 2004). Sin embargo, tenía su carga psicológica: en muchas ocasiones se daba una relación entre amo y esclavo. Muchos en la época encomiaban a la joven criada irlandesa por enviar con gran frecuencia su pequeño salario a su 
familia en Irlanda (Maguire, 1868, p. 315). Los hombres también mandaban dinero a Irlanda, pero de los 120 millones de dólares que los irlandeses enviaron a su patria desde América entre 1845 a 1865, una gran cantidad provenía de las criadas domésticas. No obstante, incluso en la esfera del servicio doméstico, los irlandeses se enfrentaban a mayores prejuicios y discriminación (Anbinder, 2010, pp. 127-128).

Una manera de eludir dicha exclusión era la de dirigir un negocio propio, pero muy pocas mujeres tenían la oportunidad de dirigir uno. Frecuentemente las mujeres con vocación empresarial se dedicaban a la venta ambulante. De hecho, la imagen de la «Irish apple woman» se hizo omnipresente en la ciudad. Estas mujeres vendían la fruta que estuviera de temporada, pero las manzanas eran las favoritas, porque aguantaban más tiempo. Las viudas a menudo vendían manzanas para poder mantenerse tras la muerte de su esposo. Algunas mujeres casadas también vendían frutas si sus hijos tenían la suficiente edad como para quedarse solos (Bayor, Meagher, 1997, p. 130). Otra labor típica de las mujeres irlandesas fue como costureras dentro de la industria textil.

Otras mujeres acababan en otros lugares menos afables. Hablamos de la industria del sexo, que especialmente dominaba en el barrio de Five Points de Nueva York. La acusación de que los burdeles del lugar forzaban a las muchachas a la prostitución contra su voluntad ha sido corroborada por pruebas actuales. Casos de este tipo se denunciaban de manera constante en la prensa de la ciudad en la época. Un ejemplo de ello es el caso de Mary O'Daniel, del condado irlandés de Waterford, una joven que fue engañada y forzada a la prostitución por su propia tía (Anbinder, 2010, pp. 210-211). Había diferentes establecimientos para este negocio; un tipo de burdel era el que usaba el atractivo del sexo como mera trampa para el robo. Es decir, la prostituta llevaba a la víctima hasta una habitación específicamente preparada para este fin (sin ventanas y con la puerta cerrada) y, mientras estaban en la cama, su cómplice robaba al hombre. A la hora de pagar por los servicios de la joven, la víctima se encontraba con que no tenía dinero y la muchacha amenazaba con denunciarlo si volvía por el barrio (Smith, 1868, pp. 390-393).

La mayoría de prostitutas habría intentado mantenerse a sí mismas a través de otros medios antes de entrar en la industria del sexo. Las ganancias semanales eran bastante superiores a la de una mujer que se dedicaba a la industria textil, al servicio doméstico o cualquier otro oficio. El alcohol también jugaba un papel importante (Sanger, 1859, pp. 489-492). Algunas mujeres afirmaban haber sido «seducidas», mientras que otras entraron en este mundo tras haber sido abandonadas por sus novios o prometidos después de haberlas dejado embarazadas (Sanger, 1859). Pocas eras las mujeres que trabajaban durante años en este negocio. La mayoría trabajaba de manera esporádica cuando no quedaba otro medio disponible para ganarse la vida. Así por ejemplo, las costureras se asociaban frecuentemente con la prostitución ocasional, ya que por lo general estaban mal pagadas y muchas veces no tenían siquiera empleo (Ellington, 1869, pp. 183-184). 
Por otro lado, la violencia contra la mujer parece haber sido común, especialmente en lugares como Five Points. El matrimonio no ofrecía ninguna garantía de seguridad. El abuso conyugal era aparentemente habitual, aunque apenas se denunciaba ante la policía. Dada la absoluta dependencia de estas mujeres a los ingresos de sus maridos, la mayoría habría dudado mucho a la hora de presentar cargos. Las violaciones era otro crimen violento contra las mujeres del que apenas hay registros. Quizá la relación tan estrecha de la comunidad evitaba tal crimen o, como el abuso conyugal, podría no haber sido denunciado. Tan solo se encuentran dos casos en los informes periodísticos de la época, ambos implicaban la violación de mujeres irlandesas por hombres no irlandeses (Anbinder, 2010, pp. 222-223).

\section{FIVE POINTS, EL BARRIO MÁS GÉLEBRE DE LA HISTORIA AMERICANA}

En la gran ciudad de Nueva York cabe destacar un barrio, que llegó a convertirse en el peor tugurio de América y en el barrio más degradado del país: Five Points. Aquí se estableció una cifra desproporcionada de irlandeses procedentes de los condados de Kerry y Sligo en la década de 1850, según confirman Tyler Anbinder y Cormac Ó'Grada. Five Points se convirtió así en el barrio más célebre de toda América en el siglo XIX, en lo que actualmente es Chinatown. Su nombre deriva de la intersección que se formaba entre las calles Anthony, Orange y Cross, en medio de la cual se situaba Paradise Square. Fue en el siglo XIX un barrio predominantemente irlandés que servirá como buen ejemplo para analizar las condiciones de vida y de trabajo de los inmigrantes irlandeses que llegaron tras la crisis de la patata.

La depravación de Five Points era tan conocida que los visitantes de fuera de la ciudad iban allí para verla con sus propios ojos. Uno de ellos fue Charles Dickens, quien puso de moda para los neoyorquinos más pudientes el acercarse y recorrer el barrio por ellos mismos, junto a una escolta policial. De hecho, el término inglés slumming, utilizado para describir este tipo de visitas, posiblemente se acuñó allí. Tales expediciones pronto se convirtieron en parte estándar de los itinerarios turísticos en la ciudad. Los informes policiales de la época confirman que los delitos estaban generalizados en el barrio. Los irlandeses eran, además, los que más sufrían por el abuso del alcohol. Hasta los niños bebían en exceso en Five Points (Browne, 1869 , p. 277). Por último, numerosos jóvenes irlandeses crearon las primeras bandas callejeras armadas de Five Points: Forty Thieves, Kerryonians, Chichesters, Shirt Tails, etc.

Ahora pasamos a examinar las condiciones de vida. Las habitaciones de las viviendas normalmente no tenían ventanas, por lo que la falta de ventilación y circulación del aire provocaban diversas enfermedades (Ernst, 1994). Otros 
convertían los sótanos, áticos e incluso las zonas de almacenamiento en apartamentos. La gran mayoría de inmuebles en Five Points estaba terriblemente abarrotada y en mal estado. Asimismo, las temperaturas extremas, tanto de calor como de frío, atormentaban a los vecinos, especialmente a los inmigrantes irlandeses, que nunca habían experimentado unas condiciones similares. Cuando hacía frío, los más desesperados recurrían a sus puertas, muebles y ropa de cama para quemarlas (Brace, 1872, pp. 204-205). Cuando los altos edificios de ladrillo comenzaron a reemplazar a los de madera, el calor se convirtió en el principal problema. La mala ventilación y circulación del aire contribuían a las agobiantes temperaturas. Estos inmigrantes irlandeses tuvieron que hacer frente a la falta de iluminación y ventilación, ambientes enrarecidos e incluso falta de limpieza corporal, pues la posibilidad de bañarse o lavar la ropa era mínima (Ernst, 1994).

En cuanto a la vida laboral, hemos de destacar que más de la mitad de los irlandeses eran trabajadores no cualificados, comparado con tan solo uno de cada 25 alemanes. La vida de un obrero era una de las más duras, peligrosas y económicamente precarias en Five Points. Durante el curso del siglo XIX, miles de niños de Five Points estaban hambrientos, sufrían abuso por parte de sus padres alcohólicos y eran forzados a trabajar en las calles para sustentarse a sí mismos o a sus familias (Anbinder, 2010, p. 110). Uno de los trabajos más conocidos para las chicas era el de vender mazorcas de maíz dulce recién preparadas (Robinson, 1854, pp. 44-49). Muchas de las que vendían maíz en agosto y septiembre trabajaban de barrenderas en invierno (Halliday, 1860, pp. 118-123). Por su parte, los niños solían trabajar como limpiabotas y vendedores de periódicos. Era especialmente fácil para los residentes de Five Points trabajar como vendedores de periódicos ya que la mayoría de estos se producían en las cercanías.

No obstante, no todo era horror y miseria en este barrio norteamericano, también fue el centro de origen del claqué, nacido por la combinación de la giga irlandesa y otros bailes afroamericanos; además fue el escenario predilecto de los Bowery Boys o los sporting men, dos de las culturas callejeras más pintorescas de la América decimonónica (Anbinder, 2010). Eran frecuentes también las organizaciones fraternales, muy populares en la América decimonónica. Los vecinos de Five Points se unieron a tales grupos, como la Ancient Order of Hibernians (AOH), que nació de una de las sociedades secretas rurales de Irlanda (Bayor, Meagher, 1997, p. 278). La organización fraternal mejor documentada de Five Points fue la Sligo Young Men's Association, fundada en 1849 por treinta hombres del condado de Sligo. Fue la primera asociación irlandesa de este tipo en Nueva York que basó su membresía en el condado de origen. Esta sociedad organizó la Sligo Light Guard con el propósito de remediar las condiciones sociales de los más humildes, para lo cual incluso prestaron dinero para que los miembros pudieran emprender sus propios negocios. 


\section{EL LEGADO DE LA GRAN HAMBRUNA}

La gran hambruna del siglo XIX fue un suceso trágico para el país y continúa como tal en el imaginario irlandés, comparable en cuanto a la gran pérdida de vidas y la emigración masiva involuntaria a sucesos como el Holocausto judío. Ni la gran hambruna ni las raíces de la emigración irlandesa han sido olvidadas. Dentro de la historia hiberno-estadounidense ha tenido un papel destacado, aunque su estudio histórico es más reciente, debido en parte al dolor y vergüenza que aún provoca en sus descendientes. De hecho, el propio gobierno irlandés ha destinado fondos para fomentar el estudio de la hambruna entre los historiadores irlandeses desde 1940. Este apoyo dio sus frutos en 1956 con la publicación de The Great Famine: Studies in Irish History. Sin embargo, con la excepción quizá de The Great Hunger de Cecil Woodham Smith, no ha habido más investigaciones al respecto hasta la actualidad, más concretamente hasta la década de los noventa, cuando se cumplió el 150 aniversario de este suceso. Precisamente en aquel año que marcaba el aniversario, en 1995, Irlanda vivía una época de prosperidad y auge económico, de renacimiento cultural y, además, contaba con un amplio y excelente círculo de investigadores en el tema (Meagher, 2005). La bibliografía al respecto también ha crecido en los últimos años.

Concretamente, la emigración en Irlanda ha jugado - y continúa haciéndolo un papel fundamental en la isla, ya que es una de las causas principales por las que el país no ha experimentado un aumento constante de la población, pese a que las tasas migratorias disminuyeron tras el final de la Primera Guerra Mundial y pese a la creación del Estado Libre Irlandés en 1922. Por tanto, es incuestionable el hecho de que la emigración es parte fundamental de la identidad irlandesa. El legado de esta continúa latente en Norteamérica hoy día, puesto que los Estados Unidos es un país que reconoce que fue construido por las manos de millones de inmigrantes que llegaron hasta sus costas. No se puede negar, por ejemplo, la gran contribución que realizaron estos irlandeses en numerosas ciudades como Nueva York o Chicago. De hecho, en la actualidad, muchos millones de norteamericanos se identifican como hiberno-estadounidenses (Glynn, 2011).

La gran hambruna se convirtió en parte intrínseca de la historia y carácter irlandés, donde sea que este habite. Esto lo demuestra su continua presencia en libros, películas, canciones, etc., que siguen rememorando esos fuertes sentimientos de los inmigrantes y los descendientes de estos. Otra prueba de ello es que numerosos estados norteamericanos incluyen esta crisis como parte de su currículo escolar. Muchas son las ciudades estadounidenses que celebran desfiles y eventos especiales el día 17 de marzo, día de San Patricio, patrón de los irlandeses. Todos estos hechos nos dejan ver la clara importancia que estos inmigrantes irlandeses adquirieron en sus nuevos países de acogida, de cómo se asentaron y entraron a formar parte de su sociedad. De hecho, los emigrantes irlandeses que huyeron tras la hambruna ejercieron una gran influencia en el desarrollo de sus países de destinos. 
El auge actual de la cultura e historia irlandesa en Estados Unidos se debe al nuevo interés por la genealogía y por la influencia desde la década de 1980 de otra oleada de inmigrantes irlandeses, muchos de los cuales llegaron al principio como ilegales. Por supuesto, el culmen de esto llegó de la mano de John F. Kennedy, elegido presidente de los Estados Unidos en 1960. Kennedy era descendiente de emigrantes irlandeses de la gran hambruna, que procedían más específicamente de los condados de Wexford y Kerry (Gray, 1999, pp. 115). Pertenecía precisamente al Partido Demócrata, siguiendo la línea política de los irlandeses que llegaron en los años de la gran hambruna. La elección de Kennedy supuso la victoria final de toda una generación de irlandeses que desde el siglo XIX habían ido abriéndose hueco en el sistema político estadounidense y su visita a Irlanda acrecentó el proceso de asimilación de los hiberno-estadounidenses con la madre patria (Coogan, 2002, p. 258).

\section{CONCLUSIONES}

Llegados a este punto, podemos concluir, por tanto, que la gran hambruna fue de especial trascendencia. Esta tragedia otorgó una serie de características a la emigración que la distingue de la de épocas anteriores y posteriores. Al ser de origen más humilde, la gran mayoría llegaba a su destino con una cantidad de dinero ínfima, por lo que tenían que establecerse en las zonas más pobres de las ciudades y trabajar en cualquier puesto que se les ofreciera. Sin embargo, no solo cambiaron los orígenes de estos emigrantes, sino también su destino. Anteriormente, el destino predilecto era Gran Bretaña, pero luego su puesto sería ocupado por Estados Unidos. Pero ni siquiera este hecho solo es capaz de explicar el por qué esta migración fue tan característica, tan solo las cifras pueden hacerlo. Estamos hablando de una gran multitud de inmigrantes como nunca antes se había visto. Un torrente que dejó tras de sí todo un legado de recuerdos, sobre todo de opresión, como no lo hizo en ningún otro lugar. Y esto fue quizá lo que supuso una mayor influencia en el futuro de una América irlandesa (Meagher, 2005). Esta emigración, asimismo, se enmarca dentro de una oleada de migraciones europeas masivas en el siglo XIX, que buscaban mejores oportunidades en América.

Otra de sus consecuencias fue un cambio en el perfil de los emigrantes. Así, la diáspora irlandesa destacó en comparación con la emigración de otros países por diversos factores. En primer lugar, por sus cifras, como acabamos de mencionar. En segundo lugar, porque emigraron muchas más mujeres irlandesas, sobre todo solteras, que hombres, hecho que no se dio en ningún otro grupo migrante y que se convirtió en una característica propia de esta migración irlandesa y un rasgo completamente distintivo del resto de inmigrantes europeos. Y en último lugar, porque, mientras que el resto de emigrantes solían regresar a su patria, los irlandeses eran mucho menos propensos a volver. 
La emigración producida por la crisis de la patata también se distingue por otro motivo: las remesas. En general, los irlandeses comprenden el grupo extranjero que más fiel fue a la hora de enviar remesas a sus países de origen y que más cantidad de dinero mandaron. Este fue un factor esencial para que, durante la gran hambruna, muchos tuvieran la oportunidad de salir de Irlanda gracias a la ayuda de familiares o amigos que ya estaban en el extranjero. Pero sería aún más importante después, pues las remesas explican, en parte, el hecho de que, aunque Irlanda comenzara el camino hacia la recuperación a finales del siglo XIX, las tasas migratorias se mantuvieran elevadas. Así pues, la persistencia es una peculiaridad intrínseca y distintiva de la experiencia migratoria irlandesa. Se estableció una firme tradición migratoria, principalmente hacia Estados Unidos. Esto conllevó, por tanto, un descenso en la población de Irlanda. Incluso la lengua gaélica sufrió graves consecuencias, e Irlanda se anglicanizó a través de la educación y la presión social por usar el inglés tras la hambruna.

De manera generalizada, los historiadores coinciden en que pocos inmigrantes han sufrido unas condiciones tan difíciles como a las que tuvieron que hacer frente los irlandeses en la América del siglo XIX (Gabbidon, Taylor Greene, 2012). En sus nuevos lugares de asentamiento, los irlandeses eran mal recibidos, tanto porque se pensaba que traían numerosas enfermedades consigo, como porque se les consideraba competencia a la hora de encontrar trabajo. Pese a todas las penurias, la migración procedente de la gran hambruna irlandesa fue fundamental en la conformación de la América irlandesa. Así, Nueva York se convirtió en una extensión de Irlanda. Los habitantes de la isla Esmeralda llevaron consigo una importante carga cultural que preparó el terreno para la evolución de la identidad de una ciudad única. Los emigrantes irlandeses se llevaron consigo, además de su cultura y tradiciones, el odio hacia Gran Bretaña, a quien culparon en todo momento del desastre de la patata. Por ello, el movimiento nacionalista irlandés adquirió auge en América y desde allí impulsó y subvencionó las acciones que se llevaban a cabo en su patria.

Sin embargo, mientras que los que pudieron huir de la funesta situación intentaban empezar de cero en otro país, los que se quedaron sufrieron la peor parte de la muerte y el hambre que reinaba en la isla en la década de 1840. Pese a ser difícil definir el número de fallecidos a causa directa de la hambruna y las enfermedades que trajo consigo, la cifra que apuntan los investigadores ronda el millón de víctimas, convirtiendo esta catástrofe natural en una de las peores de la historia más reciente. La gran hambruna no fue una conspiración de los británicos como algunos han apuntado, especialmente los nacionalistas irlandeses. Algunos autores, como Dudley Edwards y Desmond Williams (1994) han señalado, no obstante, que en estos momentos Gran Bretaña perdió una oportunidad única de implementar las reformas necesarias que quizá hubieran influido en el futuro de las relaciones anglo-irlandesas.

Como hemos visto, la gran hambruna continúa siendo una fuente de aflicción y culpa, consternación e ira para los irlandeses contemporáneos. No solo arrasó 
con la vida de millares de personas, provocó el desarraigo de otros tantos, sino que acabó con toda la vida sociocultural de Irlanda e incluso a nivel político. Ante tal tragedia, los ánimos revolucionarios se calmaron. La posición de la mujer en la familia tradicional irlandesa se vio mermada, a la vez que aumentaba la influencia de la Iglesia Católica y su imposición de una sociedad patriarcal. En todos los sentidos, la vida cotidiana de los que quedaron atrás cambió irremediablemente. Las consecuencias de esta crisis son, pues, numerosas y perviven en cierta manera hasta nuestros días tanto en Irlanda como en la comunidad irlandesa que se estableció en diferentes puntos del planeta.

\section{REFERENCIAS BIBLIOGRÁFICAS}

Anbinder, Tyler (2010). Five Points: The 19th-century New York City Neighborhood that Invented Tap Dance, Stole Elections, and Became the World's Most Notorious Slum. Nueva York: Free Press.

Bagwell, Philip (1988). The Transport Revolution 1770-1985. London: Routledge.

Bayor, Ronald H. y Meagher, Timothy J. (1997). The New York Irish. Baltimore: The Johns Hopkins University Press.

Brace, Charles Loring (1872). The Dangerous Classes of New York and Twenty Years' Work among Them. Nueva York: Wynkoop \& Hallenbeck.

Butterly, John R., y Shepherd, Jack (2010). Hunger: The Biology and Politics of Starvation. Hanover: Dartmouth College Press.

Chiswick, Barry, y Miller, Paul W. (2014). Handbook of the Economics of International Migration. Ámsterdam: Elsevier/North-Holland.

Coogan, Tim Pat (2002). Wherever Green is Worn: The Story of the Irish Diaspora. Nueva York: Palgrave Macmillan.

Diner, Hasia R. (2009). Hungering for America: Italian, Irish and Jewish Foodways in the Age of Migration. Cambridge: Harvard University Press.

Diner, Hasia R. (1983). Erin's Daughters in America: Irish Immigrant Women in the Nineteenth Century. Baltimore: The Johns Hopkins University Press.

Donnelly, Jeremy S. (2012). The Great Irish Potato Famine. Nueva York: History Press.

Edwards, Robert Dudley, y Williams, Thomas Desmond (1994). The Great Famine: Studies in Irish History 1845-52. Dublín: The Lilliput Press.

Ellington, George (1869). The Women of New York: or the Under-world of the Great City. Nueva York: New York Book Company.

Ernst, Robert (1994). Immigrant Life in New York City, 1825-1863. Siracusa: Syracuse University Press.

Fitzgerald, Patrick, y Lambkin, Brian (2009). Migration in Irish History, 1607-2007. Hampshire: Palgrave Macmillan. 
Gabbidon, Shaun L., y Greene, Helen Taylor (2012). Race and Crime. Thousand Oaks: SAGE Publications.

Garrabou, Ramón (1988). La crisis agraria de fines del siglo XIX. Barcelona: Crítica.

Glynn, Irial A. (2011). Emigration in the Atlantic: Irish, Italians and Swedes Compared (1800-1950). EGO: European History Online. Disponible en: http://www.ieg-ego. eu/glynni-2011-en

Gray, Breda (2004). Women and the Irish Diaspora. Londres: Routledge.

Gray, Peter (1999). The Irish Famine. Londres: Thames and Hudson.

Guinnane, Timothy W. (1997). The Vanishing Irish: Households, Migration and the Rural Economy in Ireland, 1850-1914. Princeton: Princeton University Press.

Halliday, Samuel Byram (1860). The Lost and Found: Or Life Among the Poor. Nueva York: Phinney, Blakeman \& Mason.

Hatton, Timothy J., y Williamson, Jeffrey G. (1998). The Age of Mass Migration: Causes and Economic Impact. Nueva York Oxford University Press.

Keating, John (1996). Irish Famine Facts. Dublín: Teagasc.

Maguire, John Francis (1868). The Irish in America. Londres: Longmans.

McIlwraith, Thomas F., y Muller, Edward K. (2001). North America: The Historical Geography of a Changing Continent. Lanham, Maryland: Rowman \& Littlefield.

Meagher, Timothy J. (2005). The Columbia Guide to Irish American History. Nueva York: Columbia University Press.

Miller Topp, Michael (2004). Racial and Ethnic Identity in the United States, 1837-1877. En Bayor, Ronald H. (coord.), The Columbia Documentary History of Race and Ethnicity in America. Nueva York: Columbia University Press, pp. 223-308.

Miller, Kerby A. (1988). Emigrants and Exiles: Ireland and the Irish Exodus to North America. Nueva York: Oxford University Press.

Morehouse, Frances (1928). The Irish Migration of the 'Forties. The American Historical Review, vol. 33, n. 3, pp. 579-592.

Ó Cuív, Éamon (2009). An Gorta Mór: The Impact and Legacy of the Great Irish Famine. St. Michael's College, University of Toronto, Canadá.

Ó'Grada, Cormac (2000). Black '47 and Beyond: The Great Irish Famine in History, Economy and Memory. Princeton: Princeton University Press.

Ó'Grada, Cormac (1995). The Great Irish Famine. Cambridge: Cambridge University Press.

Ó'Grada, Cormac (1992). Ireland's Great Famine. Refresh, n. 15, pp. 5-8.

O’Rourke, Kevin H., y Williamson, Jeffrey G. (2000). Globalization and History: The Evolution of a Nineteenth-Century Atlantic Economy. Cambridge (Massachussets): The MIT Press. 
Ranelagh, John (1994). A Short History of Ireland. Cambridge: Cambridge University Press.

Riis, Jacob A. (2011). How the Other Half Lives: Studies Among the Tenements of New York. Carlisle: Applewood Books.

Robinson, Solon (1854). Hot Corn: Life Scenes in New York Illustrated. Nueva York: De Witt and Davenport Publishers.

Sanger, William W. (1859). History of Prostitution. Nueva York: Harper \& Brothers.

Simpson, James (2001). La crisis agraria de finales del siglo XIX: una reconsideración. En Sudrià i Triay, Carles, y Tirado, Daniel A. (coord.). Peseta y protección: comercio exterior, moneda y crecimiento económico en la España de la restauración. Barcelona: Universidad de Barcelona, pp. 99-118.

Smith, Matthew Hale (1868). Sunshine and Shadow in New York. Hartford: J.B. Burr.

Travers, Pauric (1995). "There was Nothing for Me There": Irish Female Emigration, 1922-71» En O’Sullivan, Patrick (coord.) The Irish World Wide: History, Heritage, Identity, vol. 4. Leicester: Leicester University Press, pp. 146-167.

Walsh, Barbara (2002). Roman Catholic Nuns in England and Wales, 1800-1937: A Social History. Dublín: Irish Academic Press.

Woodham-Smith, Cecil (1992). The Great Hunger: Ireland 1845-1849. Londres: Penguin Group. 
